\title{
Assessing winter oilseed rape freeze injury based on Chinese HJ remote sensing data*
}

\author{
Bao SHE ${ }^{1}$, Jing-feng HUANG ${ }^{\dagger 1}$, Rui-fang GUO ${ }^{2}$, Hong-bin $\mathrm{WANG}^{3}$, Jing WANG ${ }^{1}$ \\ ( ${ }^{1}$ Institute of Agricultural Remote Sensing and Information Technology Application, College of Environmental and Resource Sciences, \\ Zhejiang University, Hangzhou 310058, China) \\ $\left({ }^{2}\right.$ Nanjing Institute of Geography and Limnology, Chinese Academy of Sciences, Nanjing 210008, China) \\ $\left({ }^{3}\right.$ Feidong Agricultural Technology Extension Center, Hefei 231600, China) \\ †E-mail: hjf@zju.edu.cn
}

Received May 30, 2014; Revision accepted Sept. 27, 2014; Crosschecked Jan. 20, 2015

\begin{abstract}
The winter oilseed rape (Brassica napus L.) accounts for about $90 \%$ of the total acreage of oilseed rape in China. However, it suffers the risk of freeze injury during the winter. In this study, we used Chinese HJ-1A/1B CCD sensors, which have a revisit frequency of $2 \mathrm{~d}$ as well as $30 \mathrm{~m}$ spatial resolution, to monitor the freeze injury of oilseed rape. Mahalanobis distance-derived growing regions in a normal year were taken as the benchmark, and a mask method was applied to obtain the growing regions in the 2010-2011 growing season. The normalized difference vegetation index (NDVI) was chosen as the indicator of the degree of damage. The amount of crop damage was determined from the difference in the NDVI before and after the freeze. There was spatial variability in the amount of crop damage, so we examined three factors that may affect the degree of freeze injury: terrain, soil moisture, and crop growth before the freeze. The results showed that all these factors were significantly correlated with freeze injury degree $(P<0.01$, two-tailed). The damage was generally more serious in low-lying and drought-prone areas; in addition, oilseed rape planted on south- and west-oriented facing slopes and those with luxuriant growth status tended to be more susceptible to freeze injury. Furthermore, land surface temperature (LST) of the coldest day, soil moisture, pre-freeze growth and altitude were in descending order of importance in determining the degree of damage. The findings proposed in this paper would be helpful in understanding the occurrence and severity distribution of oilseed rape freeze injury under certain natural or vegetation conditions, and thus help in mitigation of this kind of meteorological disaster in southern China.
\end{abstract}

Key words: Brassica napus, Freeze injury, Remote sensing, Crop monitoring, HJ-CCD doi:10.1631/jzus.B1400150 Document code: A CLC number: S127

\section{Introduction}

Oilseed rape (Brassica napus L.) is an important oil crop all over the world, and has long been one of the main sources of edible oil. Oilseed rape can be classified into spring and winter varieties according to different planting dates. China's oilseed rape culti-

\footnotetext{
Corresponding author

* Project supported by the National Natural Science Foundation of China (No. 41171276)

ORCID: Jing-feng HUANG, http://orcid.org/0000-0003-4627-6021

(C) Zhejiang University and Springer-Verlag Berlin Heidelberg 2015
}

vated area and yield all rank first in the world, in which about $90 \%$ of the national total acreage and over $90 \%$ of the yield are contributed by winter varieties (Rural Social and Economic Investigation Division, National Bureau of Statistics, 2012). Winter oilseed rape (WOR) is generally sown in autumn and matures in May in the coming year, and is usually rotated with paddy rice or other economic crops. The largest and most concentrated WOR growing regions in China lie in the middle reach of the Yangtze River basin, i.e., the southern provinces including Hubei, Hunan, Sichuan, and Anhui. 
The wintering period is crucial to the reproductive growth of WOR, during which it accomplishes the vernalization and thus flower bud can form in the future. However, it is also very likely to suffer freeze injury caused by arctic weather, e.g., frost. Frost could induce significant pigment and water loss, structural injuries, and impaired light capture capability of photosystems at the cellular scale (Oksanen et al., 2005). Furthermore, it would cause dehydrated or withered leaf blade and even canopy structure alteration (Gu et al., 2008).

It is of great importance in agricultural management to grasp the overall situation of the affected areas in good time when freeze injury occurs, so as to provide disaster relief and guide farmers to take remedial measures. Traditional field campaign usually measures the damage directly in the fields, but it is labor-intensive, time-consuming, and expensive. Remote sensing is much more efficient and lowercost technical method of acquiring geographical information. It is especially suitable for monitoring spatial and temporal variations of land surface features at regional, continental, and even global scales (Su et al., 2003). Satellite-based indicators are playing an increasingly important role in disaster monitoring and evaluating, such as flood (Townsend and Walsh, 1998; Brivio et al., 2002; Sanyal and Lu, 2005), drought (Su et al., 2003; Wan et al., 2004; Bhuiyan et al., 2006; Vicente-Serrano, 2007), pest and disease injuries (Carroll et al., 2008; Luedeling et al., 2009).

The freeze injury issues have been intensively studied using remote sensing approach for forests (Olthof et al., 2004; King et al., 2005; Currit and St. Clair, 2010), and also crops, e.g., winter wheat (Silleos et al., 2002; Feng et al., 2009; Wang et al., 2012) and sugar-cane (Tan et al., 2009). The daily minimum temperature is definitely the foremost factor for the occurrence of freeze injury. However, land surface temperature (LST) or near-ground air temperature retrieved from thermal infrared band(s) directly or indirectly, may not be readily available when frost occurs, because of the limitation of the revisit cycle or dense cloud cover. Alternatively, most studies employ various vegetation indices (VIs) derived from airborne or spaceborne sensors as the indicators of freeze injury, among which the normalized difference vegetation index (NDVI) is particularly widely ap- plied (Silleos et al., 2002; Feng et al., 2009; Tan et al., 2009; Currit and St. Clair, 2010). The affected scope and degree of the freeze injury can be estimated using the difference of VI before and after freeze, or the deviation from a normal baseline. These methods are the most prevalent for freeze injury monitoring in most of the literature, owing to the simplicity in theory and operation.

Chinese HJ multispectral sensors (including CCD and IRS) have at most $48 \mathrm{~h}$ revisit cycle and a full band set covering visible, near-infrared (NIR), short-wave infrared, mid-infrared, and thermal infrared spectral ranges, in addition to at most $30 \mathrm{~m}$ spatial resolution. HJ sensors can largely compensate for the shortage of available remote sensing data when that is due to adverse weather conditions. As far as we know, it is not common that previous freeze injury studies via remote sensing take advantage of multisensor collaboration and explore the influencing factors on the extent of damage. More critically, using remote sensing to monitor the freeze injury of WOR has not been reported previously. In this study, we took past freeze injury as a case study to assess the damage to WOR, and we also examined the relationship between degree of freeze injury and several potential environmental and vegetation factors.

\section{Study area}

Our study area is located in Hefei, which lies in the middle part of Anhui Province of China and covers the region between the Huaihe River and the Yangtze River (Fig. 1). The study area includes five counties and the total area is about $11408 \mathrm{~km}^{2}$, which spans $116^{\circ} 40^{\prime}-117^{\circ} 52^{\prime} \mathrm{E}$ and $31^{\circ} 30^{\prime}-32^{\circ} 37^{\prime} \mathrm{N}$. The terrain here is predominately low hills and the mean elevation is approximate $40 \mathrm{~m}$ above sea level. It has a subtropical humid monsoon climate and the annual average temperature is $15.7^{\circ} \mathrm{C}$, with a precipitation of about $1000 \mathrm{~mm} /$ year and more than $2100 \mathrm{~h}$ sunshine. Hefei is in traditional major oilseed rape growing areas, with a total cultivated area of 122083 ha in 2011. Feidong, one of county-level administrative units in Hefei, has the largest oilseed rape cultivation acreage in the Anhui Province. The oilseed rape varieties growing here all belong to winter series, which are sown in late Sept. to early Oct. and harvested in 
late May of the next year, and usually rotated with paddy rice.

WOR is distributed extensively in the study area, and is vulnerable to freeze injury because the region is located in the transition zone where winter wheatdominated overwintering crops (further north) turn into WOR-led crops. In early 2011, there was a period of continuous cold weather in January, with extremely low temperatures $\left(<-8{ }^{\circ} \mathrm{C}\right.$ was recorded in Chaohu) and a high frequency of cold wave invasion (Fig. 2). The oilseed rape was in seedling stage, the vast majority of WOR leaves withered up, and the plant's growth was greatly affected; as a consequence, catastrophic freeze injury occurred (Fig. 3).

\section{Data and methods}

\subsection{Data collecting and preprocessing}

The Chinese HJ satellite constellation was launched in Sept. 2008. It includes two small satellites, $1 \mathrm{~A}$ and $1 \mathrm{~B}$, each carrying two identical CCD cameras with $30 \mathrm{~m}$ spatial resolution and $360 \mathrm{~km}$ swath width. Each CCD camera has four working bands (blue, green, red, and NIR). HJ-1A and HJ-1B satellites orbit the earth in conjugate position, and the satellite constellation (including four CCD sensors altogether) provides a revisit cycle of $2 \mathrm{~d}$. In addition, an infrared multispectral sensor (IRS with four working bands) is mounted on HJ-1B. Table 1 summarizes the specifications of the multispectral sensors of $\mathrm{HJ}$ satellites.
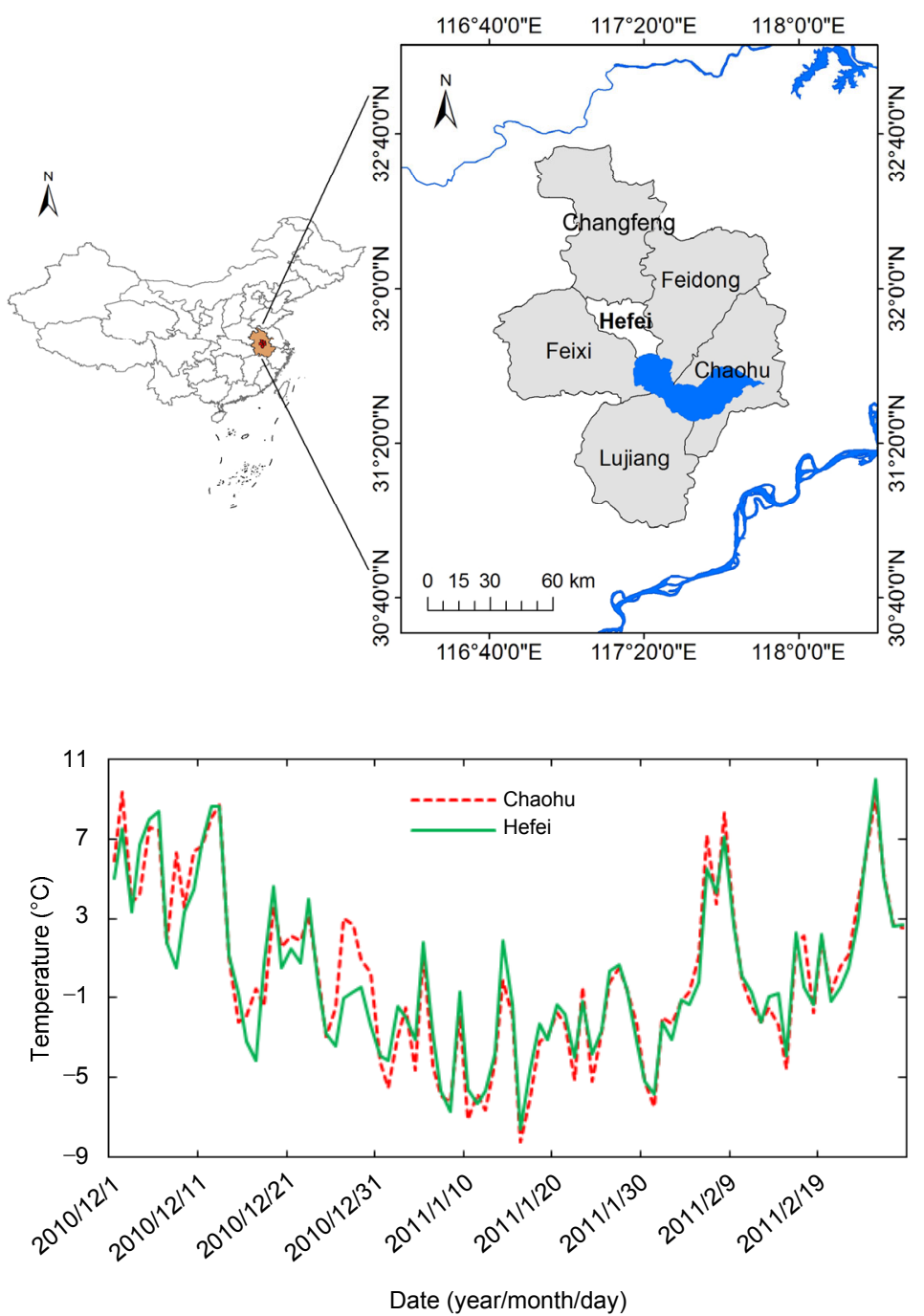

Fig. 1 Map of the study area The shaded area on the left panel shows the scope of Anhui Province and the general location of Hefei in the province. The lake within Hefei is Lake Chao and the rivers to the north and south of Hefei are the Huaihe River and the Yangtze River, respectively

Fig. 2 Curves of daily minimum temperature during the period from Dec. 2010 to Feb. 2011

The daily air temperature data were provided by the China Meteorological Data Sharing Service System, and only the data observed by Hefei and Chaohu (a county in Hefei) meteorological stations were available 
Our research involved WOR mapping, damage extent grading and influencing factor analysis, using multi-source remote sensing data (HJ-CCD dominated). Table 2 lists the specific images employed in this study and the corresponding purpose.

The above-mentioned images were obtained from the China Centre for Resources Satellite Data and Application (http://218.247.138.121/DSSPlatform/ index.html) and MODIS website (http://modis. gsfc.nasa.gov/data). HJ remote sensing data can be searched and ordered free of charge to all registered users, but only level 2 rough georeferenced products are available, which have been radiometrically calibrated and reprojected to the universal transverse mercator (UTM) projection coordinate system.

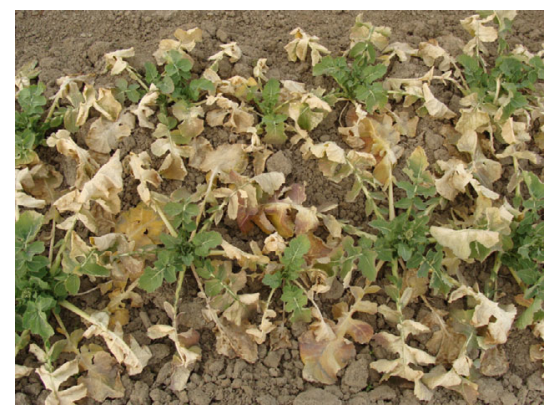

(a)

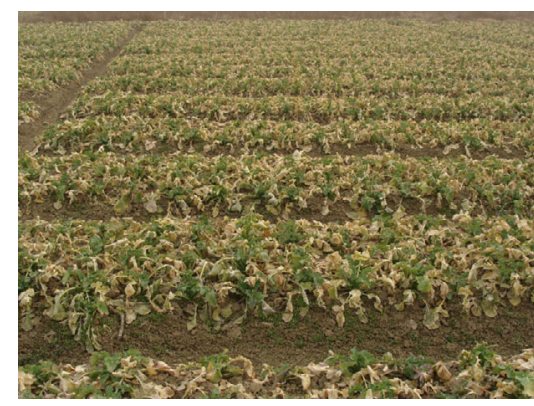

(b)
Fig. 3 Photographs of WOR with freeze injury

(a) Close-up view; (b) Perspective view. The photographs were taken in Zhonghan town (in Chaohu) on Feb. 8th, 2011 (post freeze)

Table 1 Specifications of the multispectral remote sensors onboard HJ-1A and HJ-1B satellites

\begin{tabular}{lcccccc}
\hline \multirow{2}{*}{ Platform } & Payload & Band & $\begin{array}{c}\text { Spectral range } \\
(\mu \mathrm{m})\end{array}$ & $\begin{array}{c}\text { Spatial resolution } \\
(\mathrm{m})\end{array}$ & $\begin{array}{c}\text { Swath width } \\
(\mathrm{km})\end{array}$ & $\begin{array}{c}\text { Revisit cycle } \\
(\mathrm{d})\end{array}$ \\
\hline HJ-1A/1B & CCD1 \& CCD2 & 1 & $0.43-0.52$ & 30 & 360 & 4 \\
& & 2 & $0.52-0.60$ & 30 & & \\
& & 3 & $0.63-0.69$ & 30 & & \\
HJ-1B & \multirow{2}{*}{ IRS } & 4 & $0.76-0.90$ & 30 & & \\
& & 5 & $0.75-1.10$ & 150 & & \\
& & 6 & $1.55-1.75$ & 150 & & \\
\hline
\end{tabular}

A hyperspectral imaging (HSI) spectrometer is also mounted on HJ-1A satellite with its specification not provided

Table 2 Remote sensing images used in this study

\begin{tabular}{|c|c|c|c|}
\hline Sensor & $\begin{array}{l}\text { Acquisition date } \\
\text { (year/month/day) }\end{array}$ & Path/row & Purpose \\
\hline HJ-1A-CCD2 & $2009 / 04 / 08$ & $453 / 76 \& 453 / 80$ & $\begin{array}{l}\text { Extracting the growing regions of WOR in the study area } \\
\text { in normal year (taken as the benchmark) }\end{array}$ \\
\hline HJ-1B-CCD2 & $2009 / 04 / 06$ & $452 / 76$ & $\begin{array}{l}\text { Complementing the growing regions of WOR in Chaohu } \\
\text { due to cloud cover in some areas for the image ac- } \\
\text { quired on Apr. 8th }\end{array}$ \\
\hline HJ-1B-CCD1 & $2010 / 10 / 04$ & $455 / 77$ & $\begin{array}{l}\text { Generating 'overwintering-crop' mask so as to produce } \\
\text { the WOR growing regions in early } 2011\end{array}$ \\
\hline HJ-1B-CCD1 & 2010/12/17 & $453 / 76 \& 453 / 80$ & $\begin{array}{l}\text { Generating 'overwintering-crop' mask so as to produce } \\
\text { the WOR growing regions in early } 2011\end{array}$ \\
\hline HJ-1A-CCD1 & $2010 / 12 / 31$ & $455 / 76$ & Monitoring the damage extent and its distribution \\
\hline HJ-1B-CCD1 & 2011/02/02 & $453 / 76$ & Monitoring the damage extent and its distribution \\
\hline HJ-1B-IRS & 2011/01/01 & $450 / 81$ & $\begin{array}{l}\text { LST inversion and then calculating TVDI (soil moisture } \\
\text { indicator) }\end{array}$ \\
\hline Terra-MODIS & 2011/01/01 & & $\begin{array}{l}\text { Estimating atmospheric water vapor content for LST } \\
\text { inversion }\end{array}$ \\
\hline HJ-1B-CCD2 & $2011 / 01 / 01$ & $452 / 76 \& 452 / 80$ & $\begin{array}{l}\text { Estimating emissivity for LST inversion, calculating } \\
\text { NDVI for the construction of TVDI triangular space }\end{array}$ \\
\hline Terra-MODIS & 2011/01/16 & Tile: h27v05 \& h28v05 & $\begin{array}{l}\text { Obtaining the LST of the coldest day to perform gray } \\
\text { relationship analysis }\end{array}$ \\
\hline
\end{tabular}


The preprocessing steps of HJ-CCD image data included: (1) absolute radiance conversion, with the formula and coefficients provided by the corresponding XML file in each data package; (2) geometric correction employing one Landsat-TM level 4 orthorectified granule (acquired on Jan. 14th, 2010, path/row: 121/38) covering the whole study area as the reference image, ensuring the total $\mathrm{RMS}<1$ pixel; (3) atmospheric correction using the FLAASH module in the ENVI package (the filter function file containing the spectral response function of the corresponding sensor must be input into the module, and it was generated by reference to the webpage at http:// www.cresda.com/n16/n1115/n1522/n2118/index.html); (4) mosaic and clip (in most cases two adjacent granules were needed in order to cover the whole study area).

The required preprocessing of MODIS level-1B data included radiometric calibration, geometric correction and eliminating 'bow-tie', clip, etc. Then apparent reflectance was obtained. For MOD11A1 product, reprojection and mosaic, quality assessment, rescaling, and clip were necessary, and finally a daytime $1 \mathrm{~km}$ grid LST (K) was produced.

\subsection{WOR growing region extraction}

Identifying oilseed rape based on characteristics in its flowering phase is an effective method, because it is difficult to distinguish it from other crops (mainly winter wheat) in other growing stages. In a 'normal' year, the period from mid-Mar. to mid-Apr. is the usual flowering phase for the WOR in the study area. During the main flowering period (late Mar. to early Apr.), the oilseed rape is in full bloom and shows strong yellow color, which provides a unique signature to distinguish it from other vegetation (Fig. 4a). Mahalanobis distance taxonomy as a supervised classification technique is applicable for identifying oilseed rape through remote sensing (Breckling et al., 2011), using the images collected in the main flowering period.

However, the WOR plant that suffered freeze injury would likely get a lower height and have sparse flowers, and the overall tone in the flowering phase is less prominently yellow or even dominated by dark green, which is easily confused with winter wheat at remote sensing scales. In the worst case, the WOR will be overwhelmed by soil background if it withers or is frozen to death. Therefore, it is not advisable to perform a supervised classification based on the images obtained after the damage, for the great likelihood of underestimating the areas affected by freeze injury (Fig. 4b). In addition, no satisfactory WOR map could be produced based on the images acquired in the pre-wintering period because of the weak crop signal and the strong interference from the soil background. In this study, the growing regions in a previous year were taken as a substitute, as reported by Ren et al. (2008). There was a mainly stable planting structure according to local farmers' planting customs. Unfortunately, in mid-Jan. and mid-Feb., 2010, WOR in the study area also suffered freeze injury. Because there was no obvious crop damage occurring during the 2008-2009 growing season, the flowering phase-derived growing regions in 2009 were taken as the benchmark.

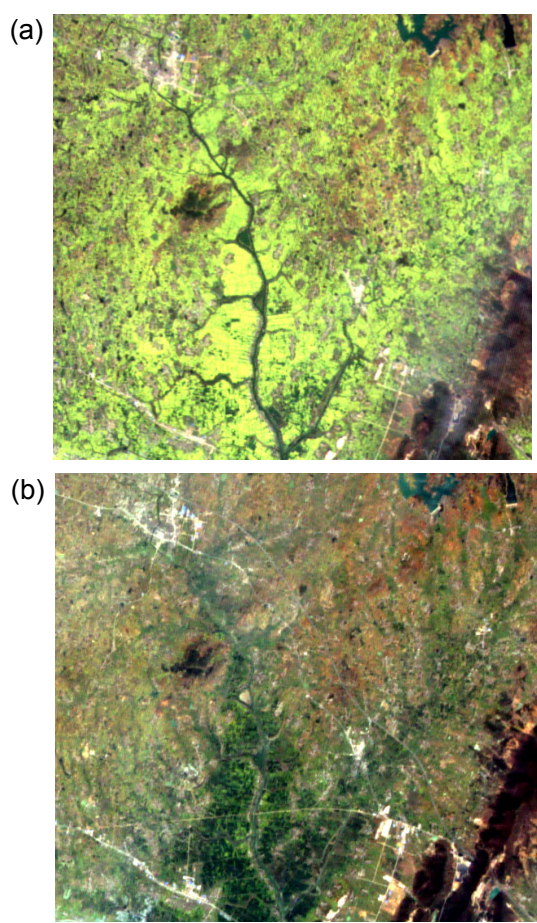

Fig. 4 True color composited CCD images (R:G:B=3:2:1) acquired in the main flowering periods of WOR

(a) Apr. 6th, 2009; (b) Apr. 4th, 2011. The figures show the most concentrated growing regions in Chaohu. It is difficult to identify WOR that has suffered freeze injury because of the consequent sparse flowers. The total cultivated areas of WOR in Chaohu were 22442 and 21336 ha in 2009 (Chaohu Municipal Bureau of Statistics, 2010) and 2011 (Hefei Municipal Bureau of Statistics, 2012), respectively (Note: for interpretation of the references to color in this figure legend, the reader is referred to the web version of this article) 
Mahalanobis distance taxonomy was applied to the images acquired on Apr. 6th and Apr. 8th, 2009 to get the growing regions of WOR in each administrative unit. However, the acreage of WOR diminished from 2009 to 2011, which meant that the previous growing regions were inapplicable to the year 2011. To cope with this problem, we proposed a so-called 'overwintering-crop mask' method to produce the new growing regions in 2011, based on the theoretical foundation that only overwintering crops (mainly WOR and winter wheat) would grow until reaching the wintering period, so NDVI would increase in value from Oct. to Dec. HJ-CCD images acquired on Oct. 4th and Dec. 17th, 2010 were adopted, and NDVIs of both time phases were calculated. Moreover, to eliminate the interference from water body on the extracted results, the normalized difference water index (NDWI) proposed by McFeeters (1996) was introduced, which was effective in identifying open water features with exclusive positive value for water body pixels. The expressions of NDVI and NDWI are taken as follows:

$$
\begin{aligned}
& \mathrm{NDVI}=\left(\rho_{\mathrm{NIR}}-\rho_{\text {red }}\right) /\left(\rho_{\mathrm{NIR}}+\rho_{\text {red }}\right), \\
& \mathrm{NDWI}=\left(\rho_{\text {green }}-\rho_{\mathrm{NIR}}\right) /\left(\rho_{\text {green }}+\rho_{\mathrm{NIR}}\right),
\end{aligned}
$$

where $\rho_{\text {green }}, \rho_{\text {red, }}$, and $\rho_{\text {NIR }}$ are the reflectance of the green, red, and NIR bands, respectively.

The pixels satisfying the following conditions were extracted: the value of NDVI increased with time (i.e., $\mathrm{NDVI}_{\text {Oct. }}<\mathrm{NDVI}_{\text {Dec. }}$ ) and being non-water pixels (i.e., $\mathrm{NDWI}_{\text {Oct. }}<0$ and $\mathrm{NDWI}_{\text {Dec. }}<0$ ), the 'overwintering-crop mask' was then produced. Note that the NDWI in the rainy season (i.e., $\mathrm{NDWI}_{\text {Oct. }}$ ) was inadequate to eliminate water body due to the regular blue-green algae bloom in Lake Chao, so we also employed that of the dry season and took their intersection. Applying the mask to modify the growing regions in 2009, the variations of WOR distribution caused by land use change or other anthropogenic activities such as farmland abandonment could be counteracted to some extent. The result was regarded as the new growing regions in 2011. However, the authors acknowledge that the alteration in planting structure of overwintering crops could not be reflected by this method.

\subsection{Freeze injury indicator determination}

We examined the applicability of different VIs generated from the four working bands assembled on HJ-CCD sensors to indicate the freeze injury of WOR. It is widely accepted that NDVI and enhanced vegetation index (EVI) are effective indicators of growth vigor, and EVI gets a lower value compared with NDVI derived from the same image (Huete et al., 1997). Wardlow et al. (2007) found that NDVI had greater sensitivity to crop condition during early greening and late senescence phases (i.e., low to intermediate green biomass levels), whereas the EVI was more sensitive at the peak of the growing season (i.e., maximum green biomass). Since WOR is in seedling stage and has low magnitude of VI value during the winter, NDVI is more appropriate for detecting or capturing subtle variations of growth status than EVI, and there is also no problem of saturation. In addition, from the perspective of data quality and for HJ-CCD sensors, the essential blue band for the construction of EVI always has the lowest imaging quality, with frequent pixel failures, and this situation is especially significant for the images acquired in winter.

NDVI connects intimately with biophysical parameters such as chlorophyll concentration, primary productivity, and green biomass for a variety of ecosystem types (Calera et al., 2004; Wang et al., 2004; Liang et al., 2005). We adopted NDVI as the indicator of freeze injury to monitor the damage by means of remote sensing.

\subsection{Freeze injury monitoring}

The freeze injury taking place in 2011 was concentrated in January and caused obvious damage. Taking into account its concentrated occurrence and devastation, we used the difference of NDVI between post- and pre-freeze to describe the damage. Two scenes of CCD image acquired on Dec. 31st, 2010 (pre-freeze, with the NDVI recorded as $\mathrm{NDVI}_{1}$ ) and Feb. 2nd, 2011 (post-freeze, with the NDVI recorded as $\mathrm{NDVI}_{2}$ ) were employed, and then NDVI corresponding to each time phase was produced. The percentage variation was calculated as

$$
\Delta^{\prime}=\frac{\mathrm{NDVI}_{2}-\mathrm{NDVI}_{1}}{\mathrm{NDVI}_{1}} \times 100 \%,
$$


which was taken as the indicator of the damage degree, and was further used for mapping the distribution of different damage levels.

\subsection{Analyses of factors influencing the degree of damage}

Taking the freeze injury occurring in 2011 as a case study, we explored the relationship between the damage degree (represented by NDVI variation) and three potential influencing factors, i.e., terrain, pre-freeze growth and soil moisture, based on the local conditions of the study area at that time.

Given the huge number of WOR pixels within the study area, as well as the existing uncertainties in the extracted WOR growing regions, 100 sampling points (Fig. 5) were selected randomly from the WOR growing regions in 2011 for the analyses. Authors informed that some anthropogenic control had been made so that these points were distributed evenly inside WOR fields. Then 100 sets of data associated with the degree of damage and environmental as well as the plant's own parameters were generated to perform correlation analyses.

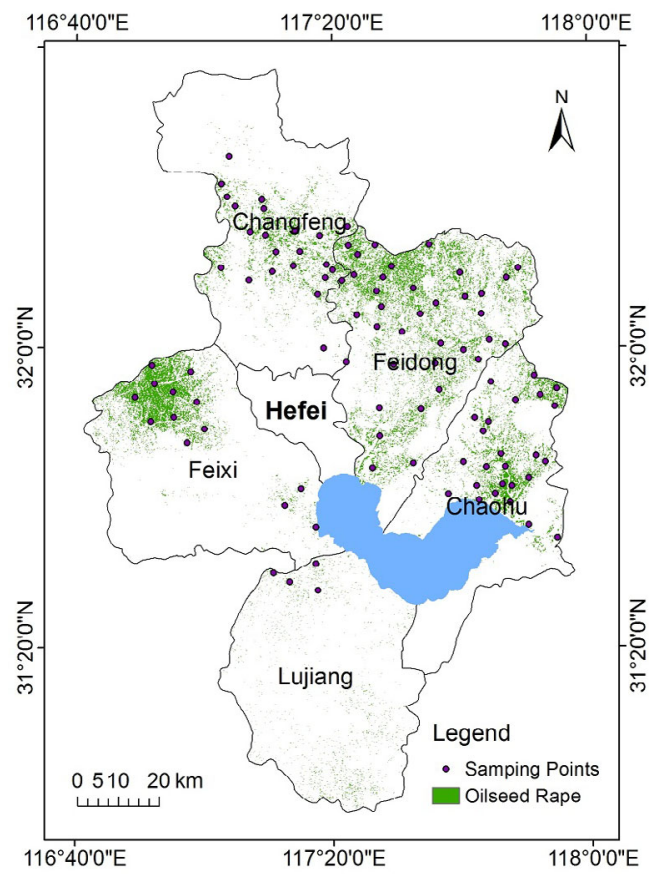

Fig. 5 Spatial distribution of the selected sampling points The distribution of WOR in Lujiang was very scattered. No sampling points were selected other than the northern part of this county so as to reduce the impact of 'mixed pixel' effect
3.5.1 Correlation between degree of damage and terrain

The altitude and aspect were used to characterize the terrain feature. ASTER GDEM Version 2 (a product of the Ministry of Economy, Trade, and Industry (METI) of Japan and the United States National Aeronautics and Space Administration (NASA)) generated from ASTER stereo images with $30 \mathrm{~m}$ spatial resolution was employed to get the altitude of the study area. The GDEM data was available at http://earthexplorer.usgs.gov (website of the United States Geological Survey), and then the aspect could be produced through surface analysis with the ArcGIS 9.3 package. All aspect values were classified into eight categories according to different directions (defined as in Table 3), and statistics on the degree of damage were performed by category and based on all WOR pixels.

3.5.2 Correlation between degree of damage and pre-freeze growth

WOR with different growth status might have a different response to freeze injury, so the relationship between degree of damage and pre-freeze growth was also investigated. As an effective indicator of growth status, NDVI derived from a scene obtained on Dec. 31st, 2010 (pre-freeze) was taken to perform the correlation analysis.

3.5.3 Correlation between degree of damage and soil moisture

Temperature-vegetation dryness index (TVDI) proposed by Sandholt et al. (2002) is a prevailing indicator of soil moisture, and the relative soil water content could be described with this index. TVDI derives from the triangular space composed of LST and vegetation index (such as NDVI), with the value ranges from 0 to 1 , and it is inversely proportional to real soil moisture. The LST retrieved from HJ-IRS thermal infrared band and NDVI derived from synchronous HJ-CCD image were employed to build the triangular space.

The mathematical expression of TVDI is taken as follows (Sandholt et al., 2002):

$$
\operatorname{TVDI}=\left(T_{\mathrm{s}}-T_{\mathrm{smin}}\right) /\left(T_{\mathrm{smax}}-T_{\mathrm{smin}}\right),
$$


where $T_{\mathrm{s}}, T_{\mathrm{smin}}$, and $T_{\mathrm{smax}}$ are LST, the minimum value of LST (wet edge), and the maximum value of LST (dry edge) for a specified NDVI range in the triangular space, respectively. Two separated linear regressions need to be performed to obtain the expressions of dry edge and wet edge. Then $T_{\mathrm{smin}}$ and $T_{\mathrm{smax}}$ can be estimated as

$$
\begin{gathered}
T_{\text {smin }}=a_{1}+b_{1} \mathrm{NDVI}, \\
T_{\text {smax }}=a_{2}+b_{2} \mathrm{NDVI},
\end{gathered}
$$

where $a_{1}, b_{1}$ and $a_{2}, b_{2}$ are the fitting coefficients for wet edge and dry edge equations, respectively.

All images applied to generate the TVDI triangular space were acquired on Jan. 1st, 2011. Since IRS sensor has only one thermal infrared band (Band 4 with a spatial resolution of $300 \mathrm{~m}$ ), for LST inversion, a generalized single-channel method proposed by Jiménez-Muñoz and Sobrino (2003) was adopted, namely

$$
\begin{gathered}
T_{s}=\gamma\left[\varepsilon^{-1}\left(\phi_{1} L_{\text {sensor }}+\phi_{2}\right)+\phi_{3}\right]+\delta, \\
\gamma=\frac{T_{\text {sensor }}^{2}}{c_{2} L_{\text {sensor }}}\left(\frac{\lambda^{4} L_{\text {sensor }}}{c_{1}}+\frac{1}{\lambda}\right), \\
\delta=-\gamma L_{\text {sensor }}+T_{\text {sensor }},
\end{gathered}
$$

where $L_{\text {sensor }}$ denotes the radiance $\left(\mathrm{W} /\left(\mathrm{m}^{2} \cdot \mu \mathrm{m} \cdot \mathrm{sr}\right)\right)$ of IRS Band 4, which is derived from radiometric calibration; $T_{\text {sensor }}$ is the brightness temperature $(\mathrm{K})$, which can be produced following the Planck equation and taking radiance as input; $\lambda$ is the central wavelength of Band 4, i.e., $11.511 \mu \mathrm{m}$ in value; $c_{1}$ and $c_{2}$ are constants, $c_{1}=1.19104 \times 10^{8} \mathrm{~W} \cdot \mu \mathrm{m}^{4} /\left(\mathrm{m}^{2} \cdot \mathrm{sr}\right)$ and $c_{2}=1.43877 \times 10^{4} \mu \mathrm{m} \cdot \mathrm{K} ; \varphi_{1}-\varphi_{3}$ can be calculated from atmospheric water vapor content, the expressions to get these three parameters are given by Duan et al. (2008) according to the specification of IRS sensor, and the input water vapor content $\left(\mathrm{g} / \mathrm{cm}^{2}\right)$ can be estimated based on Bands 2 and 19 from MODIS L1B product, using the formula proposed by Kaufman and Gao (1992); $\varepsilon$ is the emissivity of all types of ground features, which is a function of land surface types. We adopted the method proposed by Qin et al. (2004) to get the emissivity distribution, based on HJ-CCD data. Lastly, taking into account the different spatial resolutions between LST and NDVI, we resampled LST to the spatial resolution of $30 \mathrm{~m}$ (the same as NDVI) in order to build the triangular space.
3.5.4 Comprehensive analysis of freeze injuryinducing factors

The gray relationship analysis (GRA) (Deng, 1982 ) is a method of system analysis, which is primarily aimed at systems with uncertainty and incomplete datasets, enabling relational analysis of the system and the creation of models. In the study, GRA was performed to evaluate the degree of influence of each factor to the damage quantitatively, according to the resulting correlation degree. Altitude, pre-freeze growth, and soil moisture data series generated by the sampling points were taken to perform GRA with that of NDVI variation. In addition, the LST data series derived from MOD11A1 product on Jan. 16th, 2011 (the coldest day in that month) were added to the analysis, on the condition that quality assessment was conducted in advance.

\subsection{Validation}

The freeze injury index is the recognized indicator of damage level, which is field-based and generated from the field survey practices. The seedling monitoring sites are obliged to investigate the scope and degree of damage when freeze injury occurs, and parcels, which are sufficiently representative, would be chosen to perform field survey; the freeze injury index is then calculated based on statistics and taken as the ground truth degree of damage. Through consulting the specific agro-technicians who were responsible for the survey and by means of a hand-held global positioning system (GPS; Trimble GeoXT 2008, USA), the geographic positions of the investigated parcels were confirmed. Correlation analysis was performed involving the available freeze injury indices and NDVI variations of several survey plots to examine the consistency of field-measured and remote sensing derived degree of damage. The reasonableness of the monitoring results can be checked and supported in this way.

\section{Results}

\subsection{Damage-level distributions}

The freeze injury in early 2011 was serious. NDVI of WOR pixels declined significantly in most of the study area, indicating poor growth arising from the devastating effect of freeze injury. The most 
serious damage was in the northern area of Feidong and the majority of Chaohu, followed by Changfeng and the north-central parts of Feixi. The central area of Feidong was more mildly affected, and the least affected regions were mainly in Lujiang and the northwest of Feixi (Fig. 6).

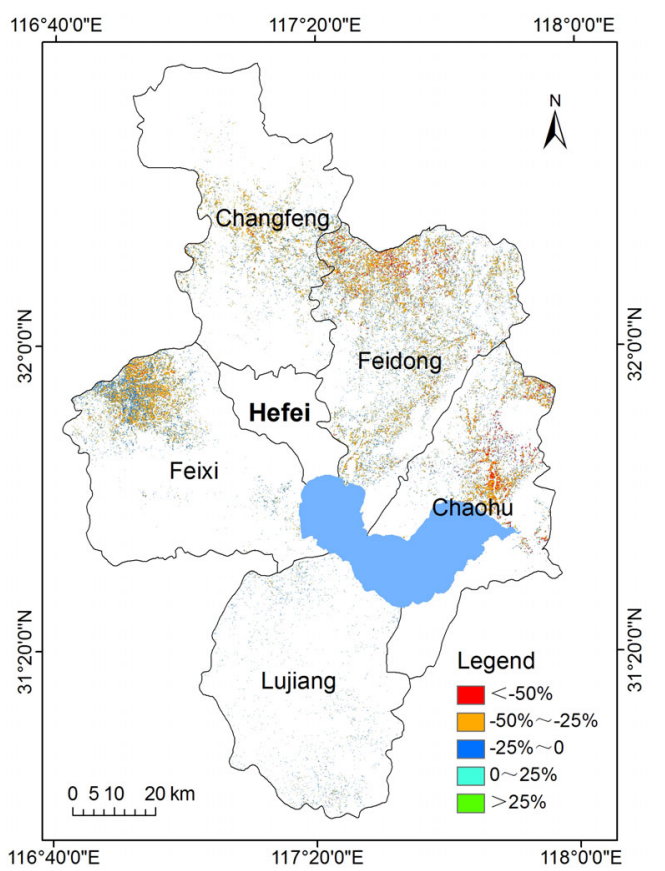

Fig. 6 Distribution of different damage levels

The degree of damage is represented by NDVI variation in percentage (post-freeze relative to pre-freeze), and a negative value indicates that the WOR has suffered freeze injury

\subsection{Analysis of influencing factors}

The altitude and degree of damage showed significant correlation $(r=0.361, P<0.01)$, and the damage tended to be milder with the increase of altitude (Fig. 7a), this agreed with the results of Currit and St. Clair (2010) working on aspen. Furthermore, the WOR cultivated on southwest-facing slopes was most vulnerable to freeze injury, followed by south- and west-facing slopes. In general, the WOR planted on south-oriented (e.g., S, SE, and SW) and westoriented (e.g., W and SW) facing slopes was inclined to suffer more severe damage, compared with other aspects (Table 3 ).

Pre-freeze growth was significantly correlated with degree of damage $(r=-0.521, P<0.01)$, and the damage tended to be more serious for the WOR growing exuberantly or with greater NDVI value (Fig. 7b).
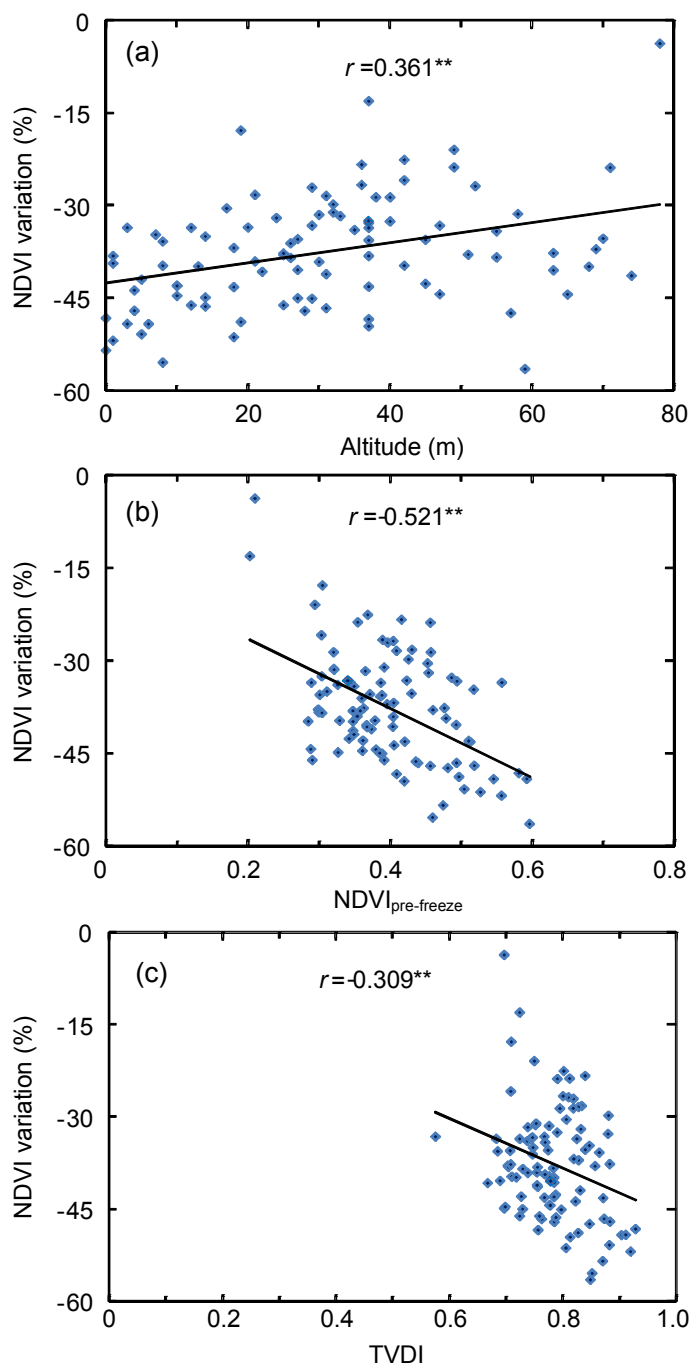

Fig. 7 Correlations between degree of damage (represented by NDVI variation in percentage) and three potential influencing factors: (a) altitude; (b) pre-freeze growth; (c) soil moisture

Sample size $=100 ;{ }^{* *} P<0.01$

Table 3 Statistics on NDVI variations according to different aspects

\begin{tabular}{cccc}
\hline Direction & $\begin{array}{c}\text { Angle range } \\
\left({ }^{\circ}\right)\end{array}$ & $\begin{array}{c}\text { Sample size } \\
\text { (pixel) }\end{array}$ & $\begin{array}{c}\text { Average } \\
\text { variation }(\%)\end{array}$ \\
\hline $\mathrm{N}$ & $337.5-22.5$ & 43816 & -35.91 \\
$\mathrm{NE}$ & $22.5-67.5$ & 90322 & -35.93 \\
$\mathrm{E}$ & $67.5-112.5$ & 119175 & -36.06 \\
$\mathrm{SE}$ & $112.5-157.5$ & 93549 & -36.17 \\
$\mathrm{~S}$ & $157.5-202.5$ & 78329 & -36.28 \\
$\mathrm{SW}$ & $202.5-247.5$ & 93709 & -36.33 \\
$\mathrm{~W}$ & $247.5-292.5$ & 119394 & -36.21 \\
$\mathrm{NW}$ & $292.5-337.5$ & 96580 & -36.04 \\
\hline
\end{tabular}

N: north; E: east; S: south; W: west 
The fitted expressions of dry edge and wet edge are given in Table 4, and the resulting TVDI is presented in Fig. 8. Significant correlation between degree of damage and soil moisture was observed $(r=-0.309, P<0.01)$, indicating that soil moisture was also a non-ignorable influencing factor on freeze injury. The degree of damage was prone to be greater in the regions where soil moisture was lower (Fig. 7c) The correlation coefficient was relatively low due to the discrepancy of spatial resolution between original LST $(300 \mathrm{~m})$ and NDVI $(30 \mathrm{~m})$, and the superimposition inaccuracies arising from the larger magnitude of georeferencing errors for IRS data (caused by its rough spatial resolution), which were particularly noticeable in the heterogeneous and fragmented land surface in the study area.

Table 4 Expressions of dry edge and wet edge for TVDI calculation

\begin{tabular}{ccc}
\hline Edge & Fitted equation & $R^{2}$ \\
\hline Dry & $y=-6.5439 x+284.25$ & 0.9154 \\
Wet & $y=5.6278 x+268.35$ & 0.8301 \\
\hline
\end{tabular}

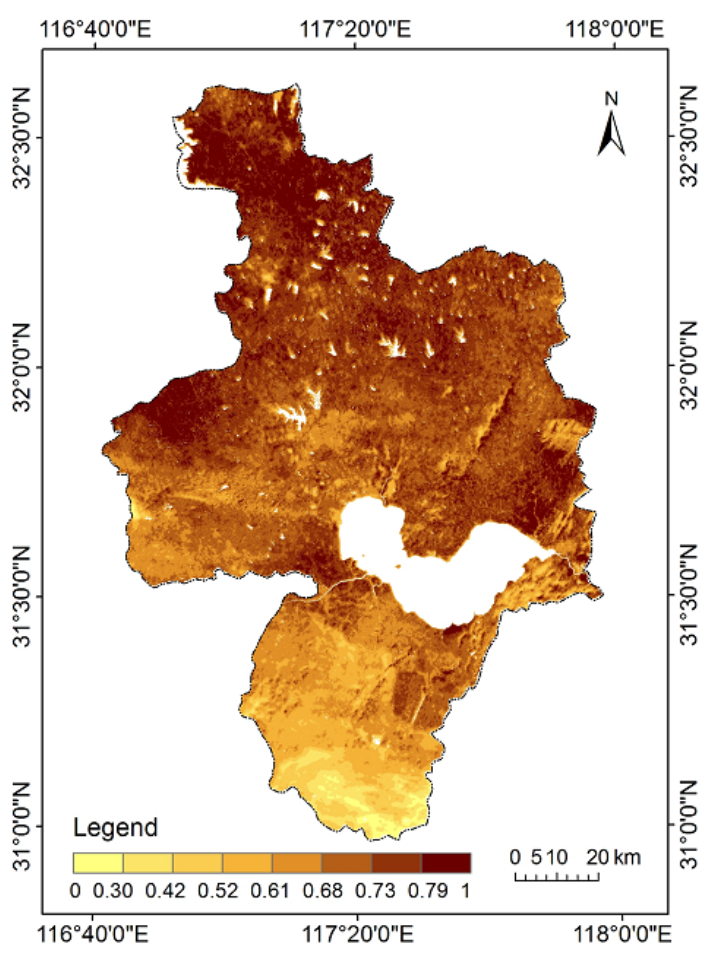

Fig. 8 Distribution of TVDI in the study area No valid data are contained in water body like Lake Chao, and abnormal low-value pixels in southern Lujiang result from cloud cover in this region
Table 5 lists the correlation degree and its corresponding rank for each factor involved in the GRA. The LST of the coldest day had the maximum correlation with damage levels, followed by soil moisture, per-freeze growth and altitude. The results of GRA also provided evidence that these factors were closely related to degree of damage.

Table 5 Influence degree of each factor to the damage

\begin{tabular}{lcc}
\hline \multicolumn{1}{c}{ Factor } & Correlation degree & Order \\
\hline Land surface temperature & 0.815 & 1 \\
Soil moisture & 0.781 & 2 \\
Pre-freeze growth & 0.768 & 3 \\
Altitude & 0.681 & 4 \\
\hline
\end{tabular}

\subsection{Validation}

The central coordinates of the survey plots are given in Table 6 . The freeze injury index and remote sensing-derived NDVI variation were the average of all investigated parcels for each monitoring site.

The freeze injury of WOR occurring at these survey plots was wholly revealed by remote sensing. Significant linear correlation between the freeze injury indices and NDVI variations of these survey plots was analyzed, showing a moderate determination coefficient $\left(R^{2}=0.541, P<0.05\right)$. This demonstrated the validity of the monitoring results from remote sensing. However, Suwan showed some difference from the other regions (Fig. 9a). A possible reason might be that the survey in this site was carried out earlier than that in other sites, when WOR responded adequately to freeze; thereafter, recovery and regrowth were in progress. When Suwan was removed from the analysis, the result was significantly improved (Fig. 9b).

\section{Discussion}

Our monitoring of the freeze injury of WOR was carried out mainly based on Chinese HJ-CCD data, and the damage occurring in Hefei in early 2011 was taken as a case study. The growing regions of WOR were obtained by means of the benchmark growing regions derived from a previous normal year and a so-called 'overwintering-crop mask' method. The distribution of different damage levels was produced referring to NDVI variations. However, some 
Table 6 Details of field survey corresponding to the freeze injury occurring in 2011

\begin{tabular}{|c|c|c|c|c|c|}
\hline \multirow{2}{*}{ County } & \multirow{2}{*}{ Town } & \multicolumn{2}{|c|}{ Coordinate of survey plot } & \multirow{2}{*}{$\begin{array}{c}\text { Launch date } \\
\text { (year/month/day) }\end{array}$} & \multirow{2}{*}{$\begin{array}{c}\text { Freeze injury index } \\
(\%)\end{array}$} \\
\hline & & Longitude $\left({ }^{\circ} \mathrm{E}\right)$ & Latitude $\left({ }^{\circ} \mathrm{N}\right)$ & & \\
\hline Chaohu & Langanji & 117.82232 & 31.97514 & $2011 / 1 / 22$ & 21.0 \\
\hline Chaohu & Suwan & 117.81077 & 31.88833 & $2011 / 1 / 20$ & 59.0 \\
\hline Chaohu & Yinping & 117.85245 & 31.55651 & $2011 / 1 / 27$ & 25.0 \\
\hline Feidong & Gucheng & 117.82819 & 32.13261 & $2011 / 1 / 23$ & 24.7 \\
\hline Feidong & Yangdian & 117.55800 & 32.12190 & $2011 / 1 / 23$ & 25.0 \\
\hline Feidong & Liangyuan & 117.54779 & 31.99475 & $2011 / 1 / 23$ & 25.0 \\
\hline Feidong & Shitang & 117.62786 & 31.90750 & $2011 / 1 / 23$ & 20.0 \\
\hline Feidong & Dianbu & 117.44138 & 31.85713 & $2011 / 1 / 23$ & 10.0 \\
\hline Feidong & Cuozhen & 117.44757 & 31.82680 & $2011 / 1 / 23$ & 16.7 \\
\hline Lujiang & Baishan & 117.35675 & 31.45573 & $2011 / 1 / 27$ & 23.3 \\
\hline
\end{tabular}

The survey statistics of freeze injury were provided by the Anhui Agricultural Technology Extension Station, China
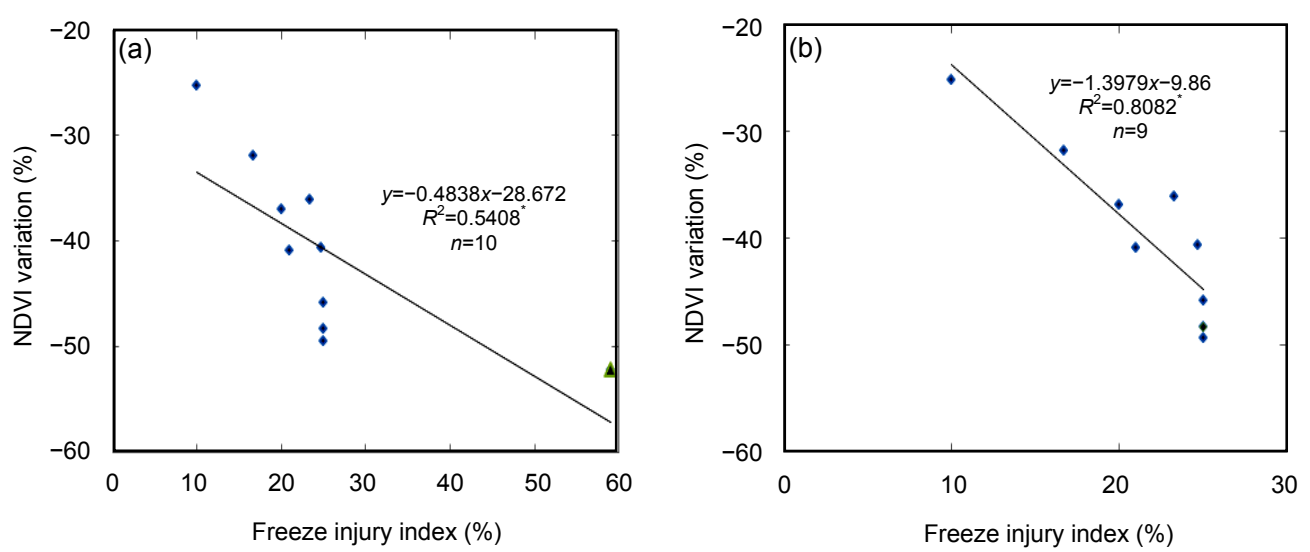

Fig. 9 Correlation between field measured-freeze injury indices and remote sensing-derived NDVI variations Correlation analyses with (a) and without (b) the data of Suwan. ${ }^{*}$ Significant at $P<0.05$. The scatter of Suwan is represented by the symbol ' $\Delta$ '

uncertainties may exist due to the mixed-pixel effect resulting from the heterogeneous and fragmented ground surface property; unfortunately, this is the general situation for most of the WOR fields in the study area. Additionally, validation of results is difficult in most cases due to the lack of the necessary field observation and survey statistics of freeze injury. In fact, only the relative severity (qualitatively) of the damage could be determined in the current study.

The freeze injury of WOR tends to be more severe in low-lying areas. Possible reasons may be that cold air accumulates in low-lying areas more easily due to its greater density, and the thicker cold air layer over depressions would induce prolonged lowtemperature period. Thus it is recommended that WOR varieties with greater cold tolerance are grown in these areas. Aspect also contributes to damage level. The WOR planted on south-oriented facing slopes has higher possibility of suffering from alternation between freezing and melting, and cells may die from this process. The prevailing northwest wind in winter may contribute to the greater damage for the WOR cultivated on west-oriented facing slopes. More detailed evidence still needs to be gained to obtain a definite explanation. For WOR planted on the aspects vulnerable to frost, remedial measures are more urgently demanded.

WOR is large-leaf crop with a high water content in the leaves, the greener the leaf, the more vulnerable to freeze injury. WOR growing exuberantly or with premature development has more risk of damage by frost $(\mathrm{Gu}$ et al., 2008). For WOR cultivation, it is not advisable to sow early or fertilize before wintering period, and nitrogen fertilizer should not be applied in particular. 
Soil moisture helps retain heat, and soil heat capacity declines with the reduction of soil moisture. Moreover, the cracked surface of dry soil further exacerbates soil heat loss and exposes the roots to the external environment, in which case the roots of WOR are more likely to be frozen when a cold wave attacks. Therefore, opportune irrigation before wintering period or moderate precipitation would be helpful in preventing the occurrence of freeze injury.

Daily minimum temperature is definitely the dominant factor in the occurrence of freeze injury. However, it is usually not practical to use remote sensing-derived LST or air temperature in freeze injury research, because dense cloud cover usually accompanies freezing weather in southern China. Microwave remote sensing has a very appealing all-weather operational capability, so it could be an effective technical means in this field. In future studies, we plan to employ passive microwave remote sensing to retrieve LST, and then apply it to freeze injury monitoring.

\section{Conclusions}

Chinese HJ multispectral sensors have the characteristics of high revisit frequency, wide spatial coverage, and moderate spatial resolution. They have distinct qualities for crop damage monitoring, and the availability of applicable images covering southern China can be convincingly guaranteed. It is feasible to monitor the freeze injury of WOR using HJ data, and a wealth of information on damage distribution could thus be provided.

WOR is extensively cultivated in Hefei region and is at risk of freeze injury. Mahalanobis distance derived benchmark growing regions combined with a mask for screening out overwintering-crops is practical for obtaining the growing regions of WOR in the wintering period. Given that freeze injury usually occurs in the seedling stage, and flowering phasebased classification is usually not effective in identifying WOR when it suffers freeze injury, this method provides a precondition to assess the damage in good time.

Freeze injury usually forms from multiple lowtemperature processes, which may occur continuously during WOR's wintering period or spanning different phenophases. NDVI can effectively reveal the difference of crop growth status between postfreeze and pre-freeze, it is qualified to serve as the indicator of freeze injury and different damage levels can thus be graded. Through correlation analysis between field measured freeze injury indices and remotely sensed NDVI variations, the validity of monitoring results by remote sensing is supported.

The prevailing natural conditions and the growth status of WOR influence the damage levels when freeze injury occurs. Terrain and pre-freeze growth, as well as soil moisture, are closely related to the degree of damage. LST is the primary factor influencing freeze injury. In conditions of low-lying areas, poor soil moisture, exuberant growth or being cultivated on south- and west-oriented facing slopes, the freeze injury of WOR is more prone to occur or be more serious. The findings proposed in this paper are of significance in guiding WOR production and the mitigation of its freeze injury in southern China.

\section{Acknowledgements}

The essential disaster data were provided by the Anhui Agricultural Technology Extension Station, China. We appreciate the professional advice and valuable information provided by Shi-feng GAO and You-wen ZHAO from the agricultural management sectors in Lujiang and Chaohu, Hefei, China, respectively. We are also grateful to Xiao-dong SONG (Zhejiang University, China) and Alan BLACKBURN (Lancaster University, UK) for their comments and suggestions, which have greatly helped improve the original version of the manuscript.

\section{Compliance with ethics guidelines}

Bao SHE, Jing-feng HUANG, Rui-fang GUO, Hong-bin WANG, and Jing WANG declare that they have no conflict of interest.

This article does not contain any studies with human or animal subjects performed by any of the authors.

\section{References}

Bhuiyan, C., Singh, R.P., Kogan, F.N., 2006. Monitoring drought dynamics in the Aravalli region (India) using different indices based on ground and remote sensing data. Int. J. Appl. Earth Obs. Geoinf., 8(4):289-302. [doi:10. 1016/j.jag.2006.03.002]

Breckling, B., Laue, H., Pehlke, H., 2011. Remote sensing as a data source to analyse regional implications of genetically modified plants in agriculture-oilseed rape (Brassica napus) in Northern Germany. Ecol. Indic., 11(4):942-950. [doi:10.1016/j.ecolind.2009.03.003] 
Brivio, P.A., Colombo, R., Maggi, M., et al., 2002. Integration of remote sensing data and GIS for accurate mapping of flooded areas. Int. J. Remote Sens., 23(3):429-441. [doi:10.1080/01431160010014729]

Calera, A., González-Piqueras, J., Melia, J., 2004. Monitoring barley and corn growth from remote sensing data at field scale. Int. J. Remote Sens., 25(1):97-109. [doi:10.1080/ 0143116031000115319]

Carroll, M.W., Glaser, J.A., Hellmich, R.L., et al., 2008. Use of spectral vegetation indices derived from airborne hyperspectral imagery for detection of European corn borer infestation in Iowa corn plots. J. Econ. Entomol., 101(5): 1614-1623. [doi:10.1603/0022-0493(2008)101[1614: UOSVID]2.0.CO;2]

Chaohu Municipal Bureau of Statistics, 2010. Chaohu Statistical Yearbook 2010. China Statistics Press, Beijing, p.264-265 (in Chinese).

Currit, N., St. Clair, S.B., 2010. Assessing the impact of extreme climatic events on aspen defoliation using MODIS imagery. Geocarto Int., 25(2):133-147. [doi:10.1080/ 10106040903051975]

Deng, J.L., 1982. Control problems of grey systems. Syst. Control Lett., 1(5):288-294. [doi:10.1016/S0167-6911(82) 80025-X]

Duan, S.B., Yan, G.J., Qian, Y.G., et al., 2008. Two singlechannel algorithms for retrieving land surface temperature using simulated HJ-1B data. Prog. Nat. Sci., 18(9): 1001-1008 (in Chinese).

Feng, M.C., Yang, W.D., Cao, L.L., et al., 2009. Monitoring winter wheat freeze injury using multi-temporal MODIS data. Agric. Sci. China, 8(9):1053-1062. [doi:10.1016/ S1671-2927(08)60313-2]

Gu, L.H., Hanson, P.J., Post, W.M., et al., 2008. The 2007 eastern US spring freeze: increased cold damage in a warming world? BioScience, 58(3):253-262. [doi:10. 1641/B580311]

Hefei Municipal Bureau of Statistics, 2012. Hefei Statistical Yearbook 2012. China Statistics Press, Beijing, p.195 (in Chinese).

Huete, A.R., Liu, H.Q., Batchily, K., et al., 1997. A comparison of vegetation indices over a global set of TM images for EOS-MODIS. Remote Sens. Environ., 59(3):440-451. [doi:10.1016/S0034-4257(96)00112-5]

Jiménez-Muñoz, J.C., Sobrino, J.A., 2003. A generalized single-channel method for retrieving land surface temperature from remote sensing data. J. Geophys. Res., 108(D22):4688. [doi:10.1029/2003JD003480]

Kaufman, Y.J., Gao, B.C., 1992. Remote sensing of water vapor in the near IR from EOS/MODIS. IEEE Trans. Geosci. Remote Sens., 30(5):871-884. [doi:10.1109/36. 175321]

King, D.J., Olthof, I., Pellikka, P.K.E., et al., 2005. Modeling and mapping damage to forests from an ice storm using remote sensing and environmental data. Nat. Hazards, 35(3):321-342. [doi:10.1007/s11069-004-1795-4]
Liang, E.Y., Shao, X.M., He, J.C., 2005. Relationships between tree growth and NDVI of grassland in the semi-arid grassland of north China. Int. J. Remote Sens., 26(13): 2901-2908. [doi:10.1080/01431160500056931]

Luedeling, E., Hale, A., Zhang, M.H., et al., 2009. Remote sensing of spider mite damage in California peach orchards. Int. J. Appl. Earth Obs. Geoinf., 11(4):244-255. [doi:10.1016/j.jag.2009.03.002]

McFeeters, S.K., 1996. The use of the normalized difference water index (NDWI) in the delineation of open water features. Int. J. Remote Sens., 17(7):1425-1432. [doi:10. 1080/01431169608948714]

Oksanen, E., Freiwald, V., Prozherina, N., et al., 2005. Photosynthesis of birch (Betula pendula) is sensitive to springtime frost and ozone. Can. J. For. Res., 35(3): 703-712. [doi:10.1139/x05-007]

Olthof, I., King, D.J., Lautenschlager, R.A., 2004. Mapping deciduous forest ice storm damage using Landsat and environmental data. Remote Sens. Environ., 89(4):484496. [doi:10.1016/j.rse.2003.11.010]

Qin, Z.H., Li, W.J., Xu, B., et al., 2004. The estimation of land surface emissivity for Landsat TM6. Remote Sens. Land Resourc., (3):28-32, 36, 41 (in Chinese). [doi:10.3969/ j.issn.1001-070X.2004.03.007]

Ren, J.Q., Chen, Z.X., Zhou, Q.B., et al., 2008. Regional yield estimation for winter wheat with MODIS-NDVI data in Shandong, China. Int. J. Appl. Earth Obs. Geoinf., 10(4): 403-413. [doi:10.1016/j.jag.2007.11.003]

Rural Social and Economic Investigation Division, National Bureau of Statistics, 2012. China Rural Statistical Yearbook 2012. China Statistics Press, Beijing, p.142, 154 (in Chinese).

Sandholt, I., Rasmussen, K., Andersen, J., 2002. A simple interpretation of the surface temperature/vegetation index space for assessment of surface moisture status. Remote Sens. Environ., 79(2-3):213-224. [doi:10.1016/S00344257(01)00274-7]

Sanyal, J., Lu, X.X., 2005. Remote sensing and GIS-based flood vulnerability assessment of human settlements: a case study of Gangetic West Bengal, India. Hydrol. Process., 19(18):3699-3716. [doi:10.1002/hyp.5852]

Silleos, N., Perakis, K., Petsanis, G., 2002. Assessment of crop damage using space remote sensing and GIS. Int. J. Remote Sens., 23(3):417-427. [doi:10.1080/014311601100 40026]

Su, Z.B., Yacob, A., Wen, J., et al., 2003. Assessing relative soil moisture with remote sensing data: theory, experimental validation, and application to drought monitoring over the North China Plain. Phys. Chem. Earth., 28(1-3): 89-101. [doi:10.1016/S1474-7065(03)00010-X]

Tan, Z.K., Ding, M.H., Wang, L.H., et al., 2009. Monitoring freeze injury and evaluating losing to sugar-cane using RS and GPS. In: Li, D.L., Zhao, C.J. (Eds.), Computer and Computing Technologies in Agriculture II, Volume 1. Springer, p.307-316. [doi:10.1007/978-1-4419-0209-2_33] 
Townsend, P.A., Walsh, S.J., 1998. Modeling floodplain inundation using an integrated GIS with radar and optical remote sensing. Geomorphology, 21(3-4):295-312. [doi:10. 1016/S0169-555X(97)00069-X]

Vicente-Serrano, S.M., 2007. Evaluating the impact of drought using remote sensing in a Mediterranean, semi-arid region. Nat. Hazards, 40(1):173-208. [doi:10.1007/s11069006-0009-7]

Wan, Z., Wang, P., Li, X., 2004. Using MODIS land surface temperature and normalized difference vegetation index products for monitoring drought in the southern Great Plains, USA. Int. J. Remote Sens., 25(1):61-72. [doi:10. 1080/0143116031000115328]

Wang, H.F., Gu, X.H., Wang, J.H., et al., 2012. Monitoring winter wheat freeze injury based on multi-temporal data. Intell. Autom. Soft Comput., 18(8):1035-1042. [doi:10. 1080/10798587.2008.10643308]

Wang, J., Rich, P.M., Price, K.P., et al., 2004. Relations between NDVI and tree productivity in the central Great Plains. Int. J. Remote Sens., 25(16):3127-3138. [doi:10. 1080/0143116032000160499]

Wardlow, B.D., Egbert, S.L., Kastens, J.H., 2007. Analysis of time-series MODIS $250 \mathrm{~m}$ vegetation index data for crop classification in the U.S. Central Great Plains. Remote Sens. Environ., 108(3):290-310. [doi:10.1016/j.rse.2006. 11.021]

\section{中文概要}

题 目: 基于国产环境减灾卫星遥感数据的油菜冻害评估

目 的: 以 2011 年 1 月发生在合肥地区的油菜冻害为案例, 利用国产环境减灾卫星数据监测其灾情分布, 探 究自然环境条件及植被长势与灾情之间的关系。

创新点: 基于遥感手段监测越冬期油菜冻害的研究鲜见报 道。鉴于受灾年份的花期影像难以准确呈现油菜 的实际空间分布, 本文提出了一套适用于灾害年 越冬时期的油菜种植区域遥感提取方法, 探索了 地形条件、越冬前长势、土壤湿度和最冷日期地 表温度对于灾情程度的影响。

方 法: 以正常年份的油菜种植区域为基准, 利用越冬作 物在越冬前生长的特性来提取受灾年份越冬时 期的油菜种植区域; 利用灾后相对于灾前的归一 化植被指数 (NDVI) 百分比变化量作为冻害监 测指标来监测灾情分布; 采用随机样本点抽取的 灾情与各影响因素数据集, 运用相关分析方法来 探讨二者之间的联系, 采用统计分析方法探讨灾 情与坡向之间的关系, 采用灰色相关分析方法考 查各影响因素对于灾情的影响程度。

结 论: 基于国产环境减灾卫星数据可以有效地监测油菜 冻害灾情, 展现不同冻害等级的空间分布; 在地 势低洼、土壤墑情差、植株长势旺盛条件下, 油 菜冻害趋于严重, 南坡向和西坡向生长的油菜受 冻相对更为严重; 各影响因素对冻害灾情的影响 程度由高到低依次为: 最冷日期的地表温度、土 壤湿度、灾前长势、海拔高度。

关键词: 油菜; 冻害; 遥感; 作物监测; 环境减灾卫星 